\title{
Cost-Effectiveness of Insulin Degludec vs. Insulin Glargine U100 in Type 1 and Type 2 Diabetes Mellitus in a UK Setting
}

\author{
Marc Evans (D) - Roopa Mehta · Jens Gundgaard · Barrie Chubb
}

Received: June 20, 2018 / Published online: August 10, 2018

(C) The Author(s) 2018

\begin{abstract}
Background: Understanding which therapeutic innovations in diabetes represent the best value requires rigorous economic evaluation. Data from randomised controlled trials and observational studies indicate that insulin degludec has a hypoglycemia advantage versus insulin glargine 100 units $/ \mathrm{mL}$ (glargine U100), the most widely prescribed basal insulin analogue in the UK. This analysis was done to more rigorously assess cost-effectiveness in a UK setting.
\end{abstract}

Enhanced Digital Features To view enhanced digital features for this article go to https://doi.org/10.6084/ m9.figshare.6871481.

Electronic supplementary material The online version of this article (https://doi.org/10.1007/s13300018-0478-1) contains supplementary material, which is available to authorised users.

\section{Evans ( $\square)$}

University Hospital Llandough, Penarth, Cardiff, UK e-mail: marclyndon1@hotmail.com

R. Mehta

Departamento de Endocrinologia y Metabolismo, Instituto Nacional de Ciencias Médicas y Nutricion Salvador Zubiran, Vasco de Quiroga 15, Mexico City, Mexico

J. Gundgaard

Novo Nordisk A/S, Søborg, Denmark

B. Chubb

Novo Nordisk, Crawley, West Sussex, UK
Methods: Data from two double-blinded, randomised, two-period crossover trials in type 1 (SWITCH 1) and type 2 (SWITCH 2) diabetes mellitus were used to assess the cost-effectiveness of degludec vs. glargine U100 with an economic model. Cost-effectiveness was analysed over a 1-year time horizon based on the different rates of hypoglycaemia and actual doses of insulin used, rather than glycaemic control due to the treat-to-target trial design.

Results: In type 1 diabetes mellitus, degludec was highly cost-effective compared with glargine U100, with an incremental cost-effectiveness ratio of $£ 984$ (increased costs of only $£ 23$ / year and improvement in participant health of 0.0232 quality-adjusted life-years (QALYs)). In type 2 diabetes mellitus, it was estimated that quality of life was improved (0.0065 QALYs gain) with degludec compared with glargine $\mathrm{U} 100$ at an increased annual cost of $£ 117$ (incremental cost-effectiveness ratio, $£ 17,939$ ). One-way sensitivity analyses showed that the results were robust to changes in parameters in both type 1 and type 2 diabetes mellitus.

Conclusions: The rigorous design of the SWITCH trials, coupled with a representative patient population and a definition of hypoglycaemia that is relevant for real-world patients, makes the results of these trials highly generalisable. The within-trial analysis has the added value of being able to include doses and event rates directly from the trials. This shortterm economic analysis estimated that IDeg 
would be cost-effective relative to IGlar U100 in both type 1 and type 2 diabetes mellitus in the UK.

Trial Registration: SWITCH 1 (NCT02034513); SWITCH 2 (NCT02030600).

Funding: Novo Nordisk, Søborg, Denmark.

Keywords: Cost-effectiveness; Diabetes; Hypoglycaemia; Insulin degludec; Insulin glargine; Pharmacoeconomics; Type 1 diabetes; Type 2 diabetes

\section{INTRODUCTION}

Healthcare systems are under increasing financial pressure from a growing chronic disease burden, particularly diabetes, which involves the cost of treating the disease as well as its complications [1]. In type 1 diabetes mellitus (T1DM), insulin replacement is an absolute requirement, and insulin is also often necessary to achieve satisfactory glycaemic control in people with more advanced type 2 diabetes mellitus (T2DM). Basal insulin analogues represent one of many therapeutic innovations in diabetes care, and understanding which treatments represent best value-thus meriting reimbursement or inclusion in guidelines or formularies-requires robust economic evaluation as well as solid clinical data. However, for evaluations to be truly representative, the data upon which they are based need to be as reflective of clinical practice as much as possible. Data from randomised clinical trials are limited because the participants enrolled are not typically reflective of those who will eventually be prescribed the medications in routine clinical care. By comparison, real-world studies of participants in regular clinical practice tend to lack the rigour of randomised controlled trials, and the data may suffer from various selection biases due to being observational and open label.

Here we report a cost-effectiveness analysis (CEA) of a novel basal insulin analogue, insulin degludec (degludec), from a UK perspective. The analysis is based on data from two unique, randomised, two-period crossover trials (SWITCH 1 in T1DM [2] and SWITCH 2 in
T2DM [3]), which overcomes many of the limitations mentioned above. Consequently, data from these two trials provide robust evidence of cost-effectiveness in order to help clinicians and payers make the most informed decisions about treatment and reimbursement.

Degludec has a distinct pharmacokinetic and pharmacodynamic profile [4-6]. Studies have shown that, depending on the type of diabetes and how hypoglycaemia is assessed (e.g. confirmed, nocturnal confirmed or severe hypoglycaemia), in the general population of enrolled patients who meet the inclusion criteria of these regulatory trials, degludec is associated with a reduction in hypoglycaemic events of between 17 and $86 \%$ compared with glargine $\mathrm{U} 100$ [7]. This is important because hypoglycaemia is a key driver of avoidable healthcare costs and decreased quality of life for participants, and it limits their ability to achieve desired glycaemic targets [8-11]. Hypoglycaemia was the primary endpoint in the SWITCH trials, and they were powered for that endpoint. The robustness and generalisability of the data from these two trials lend themselves to a confirmatory analysis of cost-effectiveness. As glargine U100 is the most prescribed basal insulin analogue in the UK, these results should be of interest to both healthcare providers and payers.

\section{METHODS}

\section{Sources of Data}

In both SWITCH trials, degludec was compared to insulin glargine 100 units $/ \mathrm{mL}$ (glargine U100). Importantly, both trials included participants with a higher risk of hypoglycaemia as determined by trial inclusion criteria (i.e. at least one of the following: experienced at least one severe hypoglycemic episode within the last year; moderate chronic renal failure; hypoglycemic symptom unawareness; exposure to insulin for longer than 5 years; or an episode of hypoglycemia (symptoms and/or blood glucose level $\leq 70 \mathrm{mg} / \mathrm{dL}$ ) within the previous 12 weeks) [3], and thus are considered to be more representative of real-world clinical 
practice than the group of randomised controlled trials conducted for regulatory purposes, which excluded such patients (BEGIN ${ }^{\circledR}$ clinical trial programme). Secondly, the SWITCH trials used a two-period (32 weeks each) crossover design in which each participant ultimately received both treatments, thereby minimising treatment bias. Finally, the trials were each double-blinded, so that neither participants nor investigators knew which insulin was being injected. Double-blinding is typically difficult to implement in large clinical trials of insulin analogues because they are marketed in proprietary, pen-type delivery devices unique to each product. In the SWITCH trials, each native formulation was administered using indistinguishable vials and syringes. Trial designs and key findings are summarised in Table 1.

\section{Economic Model}

A cost-effectiveness model with QALYs as the effect measure (also called a cost-utility model) was used to compare degludec with glargine U100 based on clinical data from SWITCH 1 [2] and SWITCH 2 [3]. The framework for the costeffectiveness model has been published previously [12].

The SWITCH trials $[2,3]$ were conducted in accordance with the Declaration of Helsinki and ICH Good Clinical Practice. Prior to trial initiation, the protocol, consent form and patient information sheet were reviewed and approved by appropriate health authorities and an independent ethics committee/institutional review board. All patients provided signed informed consent.

The modelling process is shown in Fig. 1. The cost-effectiveness of degludec was analysed over a 1-year time horizon. This represents the average annual cost-effectiveness in a steady state and not necessarily only the results after 1 year. This short-term approach based on the different rates of hypoglycaemia and actual doses of insulin used is appropriate since the treat-to-target efficacy trials required by regulatory bodies do not generally result in differences in glycaemic control between comparators; therefore, modelling long-term glycaemic control would not result in differences other than random variation. The model uses only treatment effects for which a statistically significant difference between the treatment arms is documented, and assumes that all other differences are due to random variation (i.e. equivalent to classical statistical tests where the null hypothesis could not be rejected). However, nonsignificant differences were explored in the sensitivity analysis. As the time horizon for the analysis was 1 year, no discounting (adjustment of future values to the present value) was applied. The analysis was conducted from the perspective of the UK National Health Service.

\section{Insulin Use}

Units of basal insulin used per day for the degludec and glargine U100 treatment groups were captured from the clinical trial data, and dose reductions were estimated with log-transformed end-of-trial doses, employing treatment, period, dosing time and visit as fixed effects, subject as a random effect and the logtransformed baseline dose as a covariate. For type 1 diabetes mellitus, the glargine U100 basal dose (40.58 units/day) and degludec/glargine U100 basal dose ratio (0.97 [0.94; 0.99] $95 \%$ confidence interval $[\mathrm{CI}], p<0.05)$ were derived from SWITCH 1. The bolus dose used in the glargine U100 arm (31.93 U/day) and the bolus dose ratio for the two arms (degludec/glargine U100) $(0.97$ [0.94; 1.01$] 95 \%$ CI, $p>0.05)$ were also derived from SWITCH 1 . The dose ratios, adjusted for covariates, were used to calculate the corresponding doses in the degludec arm, as can be seen in Table 2. For type 2 diabetes mellitus, only basal insulin was used (BOT, basal-only therapy). The glargine U100 basal dose (82.66 units/day) and degludec/glargine U100 basal dose ratio [0.96 (0.94; 0.98) $95 \%$ CI, $p<0.05]$ were derived from SWITCH 2.

\section{Hypoglycaemic Events}

Hypoglycaemic events were obtained by pooling data from the two full crossover periods in the SWITCH 1 [2] and SWITCH 2 trials [3]. For 
Table 1 Characteristics and primary findings of the SWITCH 1 and SWITCH 2 trials

\begin{tabular}{|c|c|c|}
\hline & $\begin{array}{l}\text { SWITCH } 1^{\mathrm{a}} \\
(\text { NCT02034513) }\end{array}$ & $\begin{array}{l}\text { SWITCH } 2^{b} \\
(\text { NCT02030600) }\end{array}$ \\
\hline Design & $\begin{array}{l}\text { Multicentre ( } 84 \text { sites in US and } 6 \text { in Poland), } \\
\text { randomised, double-blinded, two-period ( } 32 \text { weeks } \\
\text { each) crossover }\end{array}$ & $\begin{array}{l}\text { Multicentre (152 sites in US), randomised, double- } \\
\text { blinded, two-period ( } 32 \text { weeks each) crossover }\end{array}$ \\
\hline Participants & Type 1 diabetes mellitus; $n=501$ adults & Type 2 diabetes mellitus; $n=721$ adults \\
\hline Eligibility & $\begin{array}{l}\geq 1 \text { hypoglycaemia risk factors and previously treated } \\
\text { with either a basal-bolus regimen or continuous } \\
\text { subcutaneous insulin infusion for } \geq 26 \text { weeks }\end{array}$ & $\begin{array}{l}\geq 1 \text { hypoglycaemia risk factors and previously treated } \\
\text { with basal insulin with or without oral antidiabetic } \\
\text { drugs for } \geq 26 \text { weeks. Participants treated with } \\
\text { bolus/premixed insulin or sulfonylurea/meglitinide } \\
\text { within } 26 \text { weeks of the first trial visit were excluded }\end{array}$ \\
\hline \multirow[t]{2}{*}{ Treatment } & Basal-bolus therapy & Basal-only therapy \\
\hline & $\begin{array}{l}\text { Degludec or glargine U100 once daily, administered } \\
\text { either in the morning or in the evening as } \\
\text { determined by randomisation. Insulin aspart was } \\
\text { the mealtime insulin }\end{array}$ & $\begin{array}{l}\text { IDeg or glargine } \mathrm{U} 100 \text { once daily, administered either } \\
\text { in the morning or in the evening as determined by } \\
\text { randomisation. Pre-trial } \mathrm{OAD}(\mathrm{s}) \text { were continued }\end{array}$ \\
\hline Duration & $\begin{array}{l}2 \times 32 \text { weeks (titration: weeks } 1-16 \text { and } 32-48 \text {; } \\
\text { maintenance: weeks } 17-32 \text { and } 49-64 \text { ) }\end{array}$ & $\begin{array}{l}2 \times 32 \text { weeks (titration: weeks } 1-16 \text { and } 32-48 \text {; } \\
\text { maintenance: weeks } 17-32 \text { and } 49-64 \text { ) }\end{array}$ \\
\hline $\begin{array}{l}\text { Efficacy } \\
\text { findings }\end{array}$ & $\begin{array}{l}\text { Non-inferiority of degludec vs. glargine } \mathrm{U} 100 \text { with } \\
\text { respect to } \mathrm{HbA}_{1 \mathrm{c}} \text { was confirmed for the titration } \\
\text { period and the maintenance period ( } 6.9 \text { vs. } 6.8 \% \\
{[52 \mathrm{mmol} / \mathrm{mol} \text { vs. } 51 \mathrm{mmol} / \mathrm{mol} \text { ] and } 7.0 \text { vs. } 7.0 \%} \\
{[52 \mathrm{mmol} / \mathrm{mol} \text { vs. } 53 \mathrm{mmol} / \mathrm{mol} \text { ], for weeks } 32 \text { and }} \\
64 \text {, respectively) }\end{array}$ & $\begin{array}{l}\text { Non-inferiority of IDeg vs. glargine U100 with } \\
\text { respect to } \mathrm{HbA}_{1 \mathrm{c}} \text { was confirmed for the titration } \\
\text { period and the maintenance period ( } 7.1 \text { vs. } 7.0 \% \\
{[54 \mathrm{mmol} / \mathrm{mol} \text { vs. } 53 \mathrm{mmol} / \mathrm{mol}] \text { and } 7.1 \text { vs. } 7.1 \%} \\
{[54 \mathrm{mmol} / \mathrm{mol} \text { vs. } 54 \mathrm{mmol} / \mathrm{mol}] \text {, for weeks } 32 \text { and }} \\
64 \text {, respectively) }\end{array}$ \\
\hline $\begin{array}{l}\text { Safety } \\
\text { findings }\end{array}$ & $\begin{array}{l}\text { The cumulative rates of severe hypoglycaemia for the } \\
\text { three different hypoglycaemia endpoints }{ }^{c} \text { were } \\
\text { significantly lower, by } 6-36 \% \text {, depending on the } \\
\text { endpoint and time period, for degludec vs. glargine } \\
\text { U100 during both the maintenance period and the } \\
\text { full treatment period }\end{array}$ & $\begin{array}{l}\text { The cumulative rate of severe hypoglycaemia was } \\
\text { numerically lower, by } 23-51 \% \text {, for degludec vs. } \\
\text { glargine U100, and these differences were } \\
\text { statistically significant for all but one of the } \\
\text { endpoints }\end{array}$ \\
\hline
\end{tabular}

Secondary confirmatory endpoints: number of severe or BG-confirmed symptomatic nocturnal (00:01-05:59) hypoglycaemic episodes and proportion of participants with severe hypoglycaemia during the maintenance period Glargine U100, insulin glargine 100 units $/ \mathrm{mL}$

a Lane et al. [2]

b Wysham et al. [3]

c Primary endpoint: number of severe (requiring third-party aid, externally adjudicated) or blood glucose (BG)-confirmed $(<56 \mathrm{mg} / \mathrm{dL})$ symptomatic hypoglycaemic episodes during the maintenance period 


\section{Cost}

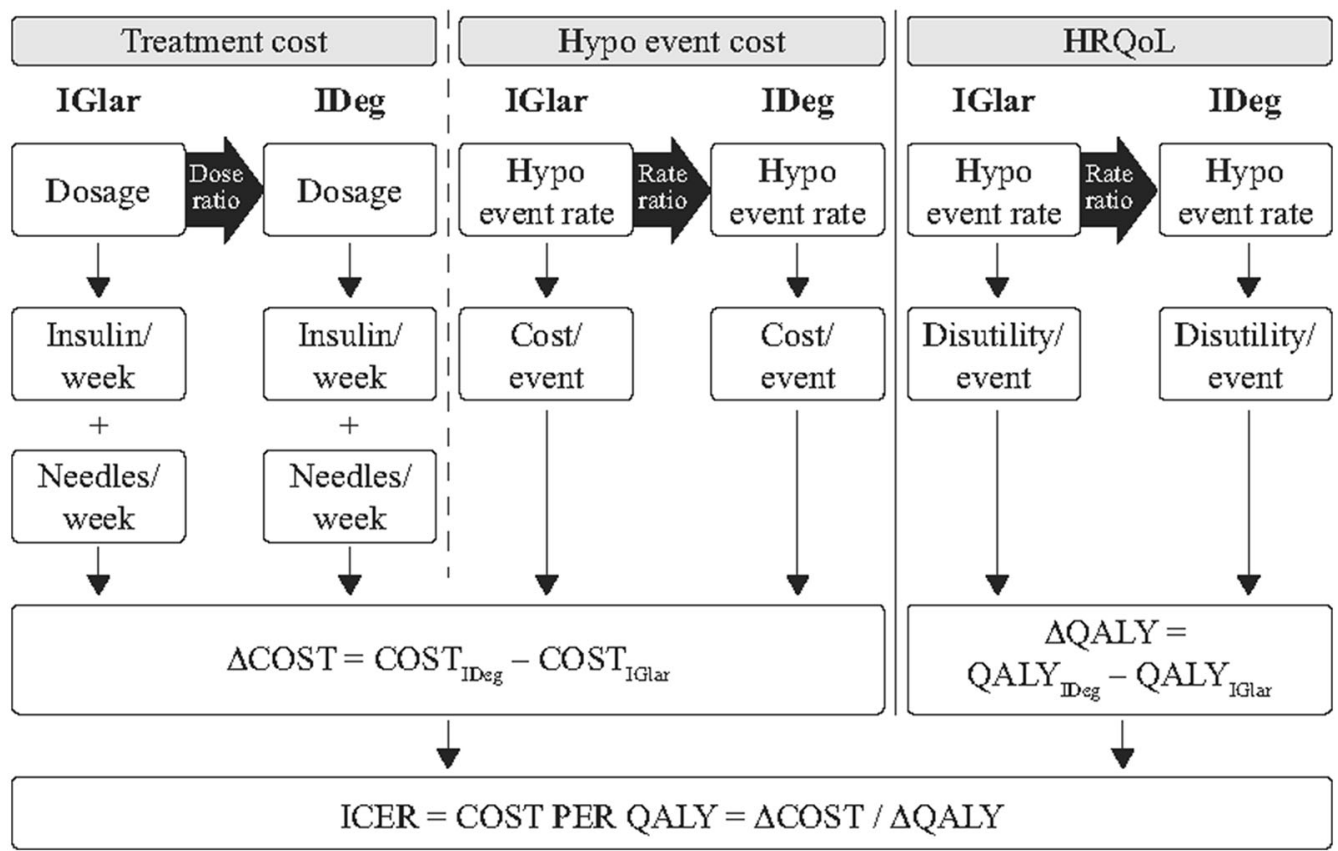

Fig. 1 Cost-effectiveness modelling of degludec. Reprinted with the permission of the publisher (Taylor \& Francis Ltd, http://www.tandfonline.com) [12]. HRQoL healthrelated quality of life, bypo hypoglycaemia, ICER

the purposes of our cost-effectiveness model, rates of hypoglycaemia were divided into three mutually exclusive groups: severe events, nonsevere events occurring during the day (diurnal including unknown time) and nonsevere events occurring during the night (nocturnal). These groups were meaningful in terms of costs and impact on quality of life. By ensuring that the groups were mutually exclusive due to stringent criteria for defining hypoglycemia, double counting of events was avoided. In both trials, non-severe hypoglycaemia was defined as a symptomatic event with a confirmed blood glucose level $<3.1 \mathrm{mmol} / \mathrm{L}(56 \mathrm{mg} / \mathrm{dL})$. Hypoglycaemic events were pre-specified: nocturnal hypoglycaemia was defined as an event occurring between 00:01 and 05:59 am, and severe hypoglycaemia was defined as an episode of hypoglycaemia requiring medical assistance and/or assistance from a third party [13].

The number of events for the rate ratios were analysed using a Poisson model with logarithm of the exposure time as offset (Table 3). The incremental cost-effectiveness ratio, $I D e g$ insulin degludec, IGlar insulin glargine U100, QALY quality-adjusted lifeyear

model included treatment, period, sequence and dosing time as fixed effects and subject as a random effect. Rate ratios and 95\% CIs used in the model for various types of hypoglycaemic event are shown in Table 3 for type 1 and type 2 diabetes mellitus. The degludec/glargine U100 rate ratios, adjusted for covariates, were applied to the glargine U100 hypoglycaemia rates per person-year to estimate the degludec hypoglycaemia rates, as can be seen in Table 3 .

\section{Treatment Costs}

Cost of insulin was based on the Monthly Index of Medical Specialties (MIMS) [14] for April 2018, which includes the updated price of insulin glargine U100. The unit costs were multiplied by the number of units per day from Table 2 . The number of needles and self-measured blood glucose (SMBG) tests were assumed to be the same in both arms (one needle and one SMBG test per injection). 
Table 2 Use of basal and bolus insulin in the SWITCH 1 and SWITCH 2 trials

\begin{tabular}{|c|c|c|c|}
\hline $\begin{array}{l}\text { Treatment } \\
\text { group }\end{array}$ & $\begin{array}{l}\text { Observed } \\
\text { glargine } \\
\text { U100 } \\
\text { (units/day) }\end{array}$ & $\begin{array}{l}\text { Dose ratio } \\
\text { (degludec/ } \\
\text { glargine } \\
\text { U100) } \\
{[95 \% \mathrm{CI}]}\end{array}$ & $\begin{array}{l}\text { Calculated } \\
\text { degludec } \\
\text { (units/day) }\end{array}$ \\
\hline
\end{tabular}

SWITCH 1: T1DM $\mathrm{B} / \mathrm{B}$

Total dose

(U)

Basal
insulin

(U)

Bolus $\quad 31.93$
insulin

(U)

SWITCH 2: T2DM ${ }_{\text {BOT }}$

\begin{tabular}{llcc}
$\begin{array}{l}\text { Total dose } \\
(\mathrm{U})\end{array}$ & & $0.96[0.94 ;$ & \\
$\begin{array}{l}\text { Basal } \\
\text { insulin } \\
(\mathrm{U})\end{array}$ & 82.66 & $0.96]$ & \\
$\begin{array}{l}\text { Bolus } \\
\text { insulin }\end{array}$ & N/A & $0.94]$ & 79.35 \\
$(\mathrm{U})$ & & N/A & N/A \\
\hline
\end{tabular}

${ }^{a}$ Observed glargine U100 units/day $x$ dose ratio

A dose ratio of 1.0 was used when the difference was not statistically significant

$B / B$ basal-bolus therapy, $B O T$ basal-only therapy, $C I$ confidence interval, glargine U100 insulin glargine 100 units/mL, N/A not applicable, NS not significant, TIDM type 1 diabetes mellitus, $T 2 D M$ type 2 diabetes mellitus

\section{Cost of Hypoglycaemia}

The costs of nonsevere nocturnal, nonsevere diurnal and severe hypoglycaemic events were derived from two sources. The cost of a severe hypoglycaemic event (type 1 diabetes mellitus, $£ 178$; type 2 diabetes mellitus BOT, £427) was calculated based on a study specifically designed to evaluate the cost of severe hypoglycaemia across Germany, Spain and the UK [15]. The cost estimate from the UK (in pounds sterling or GBP) was derived by excluding the indirect costs and adjusting for inflation using the estimates from the Hospital \& Community Health Services index [16]. The cost of a nonsevere hypoglycaemic event (daytime: type 1 diabetes mellitus, £2.44; type 2 diabetes mellitus BOT, $£ 3.48$; nocturnal: type 1 diabetes mellitus, $£ 3.04$; type 2 diabetes mellitus BOT, £5.56) was calculated based on a real-world study that investigated the frequency of self-reported nonsevere hypoglycaemic events across 11 European countries, including the UK (the Hypoglycaemia in Insulin-Treated Patients (HIT) study) [17].

\section{Impact of Hypoglycaemia on QALYs}

Quality-adjusted life-years (QALYs) were calculated by applying a disutility per hypoglycaemic event. A large-scale time trade-off (TTO) study was used to obtain the disutility incurred per hypoglycaemic event, and the following disutilities were obtained: 0.0054 and 0.0077 for nonsevere daytime and nonsevere nocturnal events, respectively, and 0.0623 for severe events based on preferences of the UK general population [18]. Severe events were not divided by the time of day at which they occurred. This was because there were no significant differences reported in the cost or utility for these events, so the impact of a severe hypoglycaemic episode was considered the same irrespective of the time at which it occurred. To estimate the incremental impact of degludec, the disutility per hypoglycaemic event was multiplied by the number of events observed in each treatment group and subtracted from a baseline level.

\section{Outcomes}

Results are presented as costs in GBP and a breakdown of the costs, effects in QALYs and incremental cost-effectiveness ratio (ICER) as cost per QALY. Two types of sensitivity analyses were conducted. The first was a one-way sensitivity analysis in which we analysed the effect of single changes in the most important parameters: hypoglycaemia rates, use of nonsignificant 
Table 3 Calculation of hypoglycaemic event rates

\begin{tabular}{|c|c|c|c|}
\hline & \multicolumn{2}{|c|}{ Nonsevere hypoglycaemia } & \multirow{2}{*}{$\begin{array}{l}\text { Severe } \\
\text { hypoglycaemia }\end{array}$} \\
\hline & Daytime & Nocturnal & \\
\hline \multicolumn{4}{|l|}{ SWITCH $1 \mathrm{~T}^{\mathrm{DDM}} \mathrm{B} / \mathrm{B}$} \\
\hline $\begin{array}{l}\text { Total events per patient per year for glargine } \\
\text { U100 }\end{array}$ & 17.18 & 3.45 & 1.05 \\
\hline $\begin{array}{l}\text { Degludec/glargine U100 hypoglycaemic event } \\
\text { rate ratio }[95 \% \mathrm{CI}]\end{array}$ & $\begin{array}{l}0.98[0.94 ; 1.03] \\
\quad p=0.457\end{array}$ & $\begin{array}{l}0.76[0.69 ; 0.84] \\
\quad p<0.0001\end{array}$ & $\begin{array}{l}0.74[0.61 ; 0.91] \\
\quad p=0.0037\end{array}$ \\
\hline Calculated degludec hypoglycaemic event rate ${ }^{a}$ & 17.18 & 2.62 & 0.78 \\
\hline \multicolumn{4}{|l|}{ SWITCH 2 T2DM $_{\text {BOT }}$} \\
\hline $\begin{array}{l}\text { Total events per patient per year for glargine } \\
\text { U100 }\end{array}$ & 1.79 & 0.86 & 0.09 \\
\hline $\begin{array}{l}\text { Degludec/glargine U100 hypoglycaemic event } \\
\text { rate ratio }[95 \% \mathrm{CI}]\end{array}$ & $\begin{array}{c}0.80[0.71 ; 0.89] \\
\quad p=0.0001\end{array}$ & $\begin{array}{l}0.76[0.64 ; 0.89] \\
\quad p=0.0011]\end{array}$ & $\begin{array}{l}0.49[0.26 ; 0.94] \\
p=0.0306\end{array}$ \\
\hline Calculated degludec hypoglycaemic event rate ${ }^{a}$ & 1.43 & 0.65 & 0.05 \\
\hline
\end{tabular}

a Total events per patient-year $\times$ rate ratio

A rate ratio of 1.0 was used when the difference was not statistically significant

$B / B$ basal-bolus therapy, BOT basal-only therapy, $C I$ confidence interval, glargine U100 insulin glargine $100 \mathrm{units} / \mathrm{mL}$, $T 1 D M$ type 1 diabetes mellitus, T2DM type 2 diabetes mellitus

rate ratios, changes in hypoglycaemia cost parameters, SMBG tests per week for degludec, hypoglycaemic event disutility, insulin doses, needles and work loss arising from hypoglycaemia. The second was a probabilistic sensitivity analysis to capture the uncertainty of the results caused by statistical uncertainty with respect to the parameter inputs. Probabilistic sensitivity analysis allows the model parameters to be varied simultaneously, based on the parameters' standard error distributions. The probabilistic sensitivity analysis was conducted using the uncertainties for all stochastic parameters in the models. Each probabilistic sensitivity analysis was run with 1000 iterations. Parameters, standard errors and distributions can be found in Table S1 of the Electronic supplementary material (ESM).

\section{RESULTS}

Costs (and the cost breakdown for pharmacy and hypoglycaemic events), QALYs and the
ICER for degludec vs. glargine U100 in type 1 and type 2 diabetes mellitus are shown in Table 4. Pharmacy costs were higher for degludec but were partly offset by hypoglycaemia costs in type 1 diabetes mellitus and type 2 diabetes mellitus. QALYs were in favour of degludec for type 1 diabetes mellitus (QALY gain degludec vs. glargine U100: 0.0232). In type 1 diabetes mellitus, the estimated ICER was small but positive (ICER $=£ 984$ ), meaning that patient health is improved in terms of QALYs at a low cost. QALYs were also in favour of degludec for type 2 diabetes mellitus (QALY gain: 0.0065). The ICER was $£ 17,939$, which falls just below the commonly accepted threshold for cost-effectiveness of $£ 20,000$ / QALY [19].

One-way sensitivity analyses showed that the results were robust to changes in parameters in both type 1 (Table S2 in the ESM) and type 2 diabetes mellitus (Table S3 in the ESM). All of the estimated ICER values were also below the normally accepted threshold of $£ 20,000-£ 30,000 / \mathrm{QALY}$, indicating that the 
Table 4 Cost-effectiveness analysis of IDeg vs. IGlar U100 in type 1 and type 2 diabetes mellitus

\begin{tabular}{|c|c|c|c|}
\hline Type 1 diabetes mellitus & Degludec $(\mathfrak{E})$ & Glargine U100 $(\mathfrak{E})$ & $\begin{array}{l}\text { Incremental cost } \\
\text { (degludec - glargine U100) }(\mathfrak{E})\end{array}$ \\
\hline Pharmacy costs (total) & 1339 & 1265 & 73 \\
\hline Insulin $^{a}$ & 685 & 611 & 73 \\
\hline Needles ${ }^{\mathrm{b}}$ & 142 & 142 & 0 \\
\hline SMBG tests ${ }^{c}$ & 512 & 512 & 0 \\
\hline Hypoglycaemic events (total) & 189 & 239 & -51 \\
\hline Nonsevere daytime events & 42 & 42 & 0 \\
\hline Nonsevere nocturnal events & 8 & 10 & -3 \\
\hline Severe events & 139 & 187 & -48 \\
\hline Total costs & 1527 & 1505 & 23 \\
\hline \multicolumn{4}{|l|}{ Effects } \\
\hline QALYs & 0.7741 & 0.7509 & 0.0232 \\
\hline ICER (cost per QALY) & & & 984 \\
\hline Type 2 diabetes mellitus & Degludec $(\boldsymbol{E})$ & Glargine U100 $(\mathfrak{E})$ & $\begin{array}{l}\text { Incremental cost } \\
(\text { degludec - glargine U100) }(f)\end{array}$ \\
\hline Pharmacy costs (total) & 1064 & 924 & 140 \\
\hline Insulin $^{a}$ & 900 & 760 & 140 \\
\hline Needles ${ }^{\mathrm{b}}$ & 35 & 35 & 0 \\
\hline SMBG tests ${ }^{c}$ & 128 & 128 & 0 \\
\hline Hypoglycaemic events (total) & 28 & 51 & -23 \\
\hline Nonsevere daytime events & 5 & 6 & -1 \\
\hline Nonsevere nocturnal events & 4 & 5 & -1 \\
\hline Severe events & 20 & 40 & -20 \\
\hline Total costs & 1092 & 975 & 117 \\
\hline \multicolumn{4}{|l|}{ Effects } \\
\hline QALYs & 0.8864 & 0.8798 & 0.0065 \\
\hline ICER (cost per QALY) & & & 17,939 \\
\hline
\end{tabular}

Numbers in the table are rounded to the nearest integer for costs and to four decimal places for QALYs

Glargine U100 insulin glargine 100 units/mL, ICER incremental cost-effectiveness ratio, QALYs quality-adjusted life-years, $S M B G$ self-measured blood glucose

${ }^{a}$ IDeg (in FlexTouch ${ }^{\circledR}$ pen) $£ 46.60$ for 1500 units, resulting in cost/unit $£ 0.031$; Lantus ${ }^{\circledR}$ (in Solostar ${ }^{\circledR}$ pen) $£ 37.77$ for 1500 units, resulting in cost/unit $£ 0.025$; insulin aspart (in FlexPen ${ }^{\circledR}$ ) $£ 30.60$ for 1500 units, resulting in cost/unit $£ 0.020$

b BD MicroFine ${ }^{\circledR} 5 \mathrm{~mm}: £ 9.69$ per 100 needles, resulting in a needle price of $£ 0.097$

c SMBG test costs of $£ 0.3507$ based on the use of one Aviva test strip and one FastClix lancet per test 
results were robust to changes in assumptions and parameters. Probabilistic sensitivity analyses also show that degludec is cost-effective (Figs. S1 and S2 in the ESM). At a threshold value of $£ 20,000 / \mathrm{QALY}$, the probability that degludec will be cost-effective against glargine $\mathrm{U} 100$ is $99.8 \%$ for type 1 and $62.1 \%$ for type 2 diabetes mellitus.

\section{DISCUSSION}

This short-term analysis leveraged results from two unique, double-blind, randomised, controlled, two-period crossover trials (SWITCH 1 [2] and SWITCH 2 [3]) to demonstrate the costeffectiveness of degludec vs. glargine U100 in participants in the UK with type 1 or type 2 diabetes. To enhance the generalisability of the results, the SWITCH trial data were based on a more clinically relevant definition of hypoglycaemia (i.e. including only symptomatic bloodglucose confirmed events), and included participants who were more representative of those in regular clinical practice (i.e. with a history of hypoglycaemia) than those used in the series of randomised, parallel-group, open-label trials that comprised the BEGIN ${ }^{\circledR}$ clinical development programme for degludec. By including participants at higher risk of hypoglycaemia, we considered the sample to be more representative of participants in the UK. Despite the inclusion of these participants in the SWITCH trials, the rates were still somewhat lower than reported in real-world studies [20].

These results are consistent with an analysis that used hypoglycaemia rates from participants with type 2 diabetes mellitus from the BEGIN ${ }^{\circledR}$ clinical development programme for degludec. Analyses using data from BEGIN ${ }^{\circledR}$ suggested an ICER between $£ 13,078$ and $£ 15,795$ [21]. A reanalysis of the cost-effectiveness of degludec vs. glargine U100 suggested even lower ICERs [22]. However, changes in the prices of degludec and glargine U100 make comparisons with previous analyses difficult.

These findings are also consistent with evidence from observational studies in type 1 diabetes mellitus. For example, one retrospective single-centre case series of 35 consecutive participants with type 1 diabetes mellitus in real-world practice in the UK concluded that degludec was highly cost-effective for participants who switched from either glargine U100 or insulin detemir [23]. Degludec was dominant against glargine U100/insulin detemir; even when benefits beyond hypoglycaemia reduction were excluded, the predicted cost per QALY of switching to degludec was $£ 10,754$ projected over a lifetime. Those results should be considered conservative, as the cost of degludec in the UK has recently been lowered. Analysis of data from a larger observational study of 476 consecutive participants with type 1 diabetes mellitus in Sweden also concluded that degludec was dominant compared with glargine U100 [24].

Currently marketed basal insulins in the UK include the basal insulin analogues studied here (degludec and glargine U100) as well as neutral protamine Hagedorn insulin (NPH). In the UK, the most widely prescribed basal insulin is glargine U100. Furthermore, for health economic analysis, the next best alternative is usually considered the appropriate comparator [25]. Compared with NPH, in type 1 diabetes mellitus, basal insulin analogues have been shown to provide small but statistically significant improvements in $\mathrm{HbA}_{1 \mathrm{c}}$ and clinically important reductions in nocturnal and symptomatic hypoglycaemia [26]. The reduced risk of nocturnal hypoglycaemia with an all-analogue basal-bolus regimen compared with a human insulin basal-bolus regimen has been demonstrated in people with type 1 diabetes mellitus prone to recurrent severe hypoglycaemia [27]. In type 2 diabetes mellitus, basal insulin analogues are also associated with a significantly reduced risk of nocturnal and symptomatic hypoglycaemia [28]. In addition, the SWITCH trials did not include any direct comparison vs. $\mathrm{NPH}$, and indirect comparisons were out of the scope of this analysis. There are also no other published data that directly compare degludec and NPH. However, a systematic review of 15 modelling studies found that another basal insulin analogue, insulin detemir, was cost-effective vs. NPH and at least as cost-effective as glargine U100 in both type 1 and type 2 diabetes mellitus [29]. Data from the UK have also 
shown that insulin detemir was cost-effective vs. NPH in type 1 diabetes mellitus [30, 31].

This study is limited (as are all model-based evaluations) by the need to estimate input parameters. Some of our cost estimates were derived from multiple sources and national settings, and therefore may not reflect the true health economic impact in the UK. In contrast, the use of data from actual trial results for insulin doses and hypoglycaemia rates is a strength of the study. Furthermore, the sensitivity analysis demonstrated that the results were robust, and using rates of hypoglycaemia from other published sources leads to even more improved cost-effectiveness results. A new, more concentrated formulation of insulin glargine, 300 units/mL (IGlar U300), has recently been introduced; however, a cost-effectiveness analysis of IGlar U300 vs. degludec using head-to-head data will not be possible until clinical trials are conducted. Finally, although an association between hypoglycemic events and subsequent cardiovascular outcomes and mortality was demonstrated previously, a causal link is yet to be established beyond doubt, so we were unable to include it in a costeffectiveness analysis [32-36].

\section{CONCLUSION}

Analysis of data from a pair of rigorously designed randomised controlled trials in both type 1 (SWITCH 1) and type 2 (SWITCH 2) diabetes mellitus indicates that degludec is a cost-effective treatment option vs. glargine U100 in participants with type 1 diabetes mellitus using basal-bolus therapy and in participants with type 2 diabetes mellitus using basalonly therapy in the UK. The balance of internal and external validity achieved with the SWITCH trials in terms of trial design and population inclusion adds important information to the value discussion.

\section{ACKNOWLEDGEMENTS}

Firstly, we wish to thank the patients who participated in the SWITCH 1 and SWITCH 2 trials.
Funding. This manuscript and article processing charges were supported by Novo Nordisk, Søborg, Denmark.

Role of Funding Source. Novo Nordisk contributed to the study design, statistical analyses, data interpretation, manuscript preparation and the decision to submit this manuscript for publication. All of the authors had access to the study data and take full responsibility for the content of the manuscript and the decision to submit it for publication.

Medical Writing, Editorial, and Other Assistance. Medical writing and submission support were provided by Gary Patronek and Beverly La Ferla of Watermeadow Medical, an Ashfield company, part of UDG Healthcare plc, funded by Novo Nordisk. We also thank Deniz Tutkunkardas (Novo Nordisk) for his review and input to the manuscript.

Authorship. All named authors meet the International Committee of Medical Journal Editors (ICMJE) criteria for authorship for this article, take responsibility for the integrity of the work as a whole, and have given their approval for this version to be published.

Authorship Contributions. Individual contributions were as follows: study concept and design: Barrie Chubb, Jens Gundgaard; acquisition, analysis or interpretation of data: Marc Evans, Roopa Mehta, Jens Gundgaard, Barrie Chubb; health economic analysis: Barrie Chubb, Jens Gundgaard; writing and review of manuscript: Marc Evans, Roopa Mehta, Jens Gundgaard, Barrie Chubb.

Disclosures. Marc Evans has received honoraria and research awards from Novo Nordisk, Sanofi-Aventis, MSD and Novartis. Roopa Mehta has received honoraria from Novo Nordisk, Boehringer Ingelheim, Amgen, AstraZeneca, Janssen, MSD, Novartis, Stendahl and Abbott. Jens Gundgaard is an employee of Novo Nordisk and also holds stock in Novo Nordisk. Barrie Chubb is also an employee of Novo Nordisk and also holds stock in Novo Nordisk. 
Compliance with Ethics Guidelines. The SWITCH trials [2, 3] were conducted in accordance with the 1964 Helsinki Declaration and its later amendments and ICH Good Clinical Practice. Prior to trial initiation, the protocol, consent form, and patient information sheet were reviewed and approved by appropriate health authorities and an independent ethics committee/institutional review board. All patients provided signed informed consent.

Data Availability. The datasets generated during and/or analysed during the current study are available from the corresponding author on reasonable request.

Open Access. This article is distributed under the terms of the Creative Commons Attribution-NonCommercial 4.0 International License (http://creativecommons.org/licenses/ by-nc/4.0/), which permits any noncommercial use, distribution, and reproduction in any medium, provided you give appropriate credit to the original author(s) and the source, provide a link to the Creative Commons license, and indicate if changes were made.

\section{REFERENCES}

1. Levin P. The cost-effectiveness of insulin glargine vs. neutral protamine Hagedorn insulin in type 2 diabetes: a focus on health economics. Diabetes Obes Metab. 2008;10(Suppl. 2):66-75.

2. Lane W, Bailey TS, Gerety G, Gumprecht J, PhilisTsimikas A, Hansen CT, et al. Effect of insulin degludec vs insulin glargine U100 on hypoglycemia in patients with type 1 diabetes: the SWITCH 1 randomized clinical trial. JAMA. 2017;318:33-44.

3. Wysham C, Bhargava A, Chaykin L, de la Rosa R, Handelsman Y, Troelsen LN, et al. Effect of insulin degludec vs insulin glargine U100 on hypoglycemia in patients with type 2 diabetes: the SWITCH 2 randomized clinical trial. JAMA. 2017;318:45-56.

4. Heise T, Nosek L, Bottcher SG, Hastrup H, Haahr H. Ultra-long-acting insulin degludec has a flat and stable glucose-lowering effect in type 2 diabetes. Diabetes Obes Metab. 2012;14:944-50.

5. Heise T, Korsatko S, Nosek L, Coester HV, Deller S, Roepstorff C, et al. Steady state is reached within
2-3 days of once-daily administration of degludec, a basal insulin with an ultralong duration of action. J Diabetes. 2016;8:132-8.

6. Heise T, Hermanski L, Nosek L, Feldman A, Rasmussen S, Haahr H. Insulin degludec: four times lower pharmacodynamic variability than insulin glargine under steady-state conditions in type 1 diabetes. Diabetes Obes Metab. 2012;14:859-64.

7. Ratner R, Gough SC, Mathieu C, Del Prato S, Bode $\mathrm{B}$, Mersebach $\mathrm{H}$, et al. Hypoglycaemia risk with insulin degludec compared with insulin glargine in type 2 and type 1 diabetes: a pre-planned metaanalysis of phase 3 trials. Diabetes Obes Metab. 2013;15:175-84.

8. Farmer AJ, Brockbank KJ, Keech ML, England EJ, Deakin CD. Incidence and costs of severe hypoglycaemia requiring attendance by the emergency medical services in South Central England. Diabet Med. 2012;29:1447-50.

9. Harris SB, Khunti K, Landin-Olsson M, Galbo-Jørgensen CB, Bøgelund M, Chubb B, et al. Descriptions of health states associated with increasing severity and frequency of hypoglycemia: a patientlevel perspective. Patient Prefer Adherence. 2013;7:925-36.

10. Heller SR, Frier BM, Hersløv ML, Gundgaard J, Gough SC. Severe hypoglycaemia in adults with insulin-treated diabetes: impact on healthcare resources. Diabet Med. 2016;33:471-7.

11. Willis WD, Diago-Cabezudo JI, Madec-Hily A, Aslam A. Medical resource use, disturbance of daily life and burden of hypoglycemia in insulin-treated patients with diabetes: results from a European online survey. Expert Rev Pharmacoecon Outcomes Res. 2013;13:123-30.

12. Evans M, Wolden M, Gundgaard J, Chubb B, Christensen T. Cost-effectiveness of insulin degludec compared with insulin glargine in a basal-bolus regimen in patients with type 1 diabetes mellitus in the UK. J Med Econ. 2015;18:56-68.

13. Seaquist ER, Anderson J, Childs B, Cryer P, DagogoJack S, Fish L, et al. Hypoglycaemia and diabetes: a report of a workgroup of the American Diabetes Association and the Endocrine Society. Diabetes Care. 2013;36:1384-95.

14. Haymarket Media Group. MIMS (Monthly Index of Medical Specialties). Available at www.mims.co.uk. Last accessed 28 June 2018.

15. Hammer M, Lammert M, Mejías SM, Kern W, Frier $\mathrm{BM}$. Costs of managing severe hypoglycaemia in three European countries. J Med Econ. 2009;12:281-90. 
16. HCHS: The Hospital \& Community Health Services (HCHS) index. Available at https://kar.kent.ac.uk/ 65559/40/65559_rep_UCR-2017-v13finalKAR.pdf. Last accessed 16 April 2018.

17. Chubb B, Tikkanen C. The cost of non-severe hypoglycaemia in Europe. Value Health. 2015;18:A611.

18. Evans M, Khunti K, Mamdani M, Galbo-Jørgensen $\mathrm{CB}$, Gundgaard J, Bøgelund M, et al. Health-related quality of life associated with daytime and nocturnal hypoglycaemic events: a time trade-off survey in five countries. Health Qual Life Outcomes. 2013;11:90.

19. Adalsteinsson E, Toumi M. Benefits of probabilistic sensitivity analysis-a review of NICE decisions. J Mark Access Health Policy. 2013;1. https://doi. org/10.3402/jmahp.v1i0.21240.

20. Elliott L, Fidler C, Ditchfield A, Stissing T. Hypoglycemia event rates: a comparison between realworld data and randomized controlled trial populations in insulin-treated diabetes. Diabetes Ther. 2016;7:45-60.

21. Evans M, Wolden M, Gundgaard J, Chubb B, Christensen T. Cost-effectiveness of insulin degludec compared with insulin glargine for patients with type 2 diabetes treated with basal insulinfrom the UK health care cost perspective. Diabetes Obes Metab. 2014;16:366-75.

22. Evans M, Chubb B, Gundgaard J. Cost-effectiveness of insulin degludec versus insulin glargine in adults with type 1 and type 2 diabetes mellitus. Diabetes Ther. 2017;8:275-91.

23. Evans M, McEwan P, Foos V. Insulin degludec early clinical experience: does the promise from the clinical trials translate into clinical practice-a casebased evaluation. J Med Econ. 2015;18:96-105.

24. Landstedt-Hallin L, Gundgaard J, Ericsson A, Ellfors-Zetterlund S. Cost-effectiveness of switching to insulin degludec from other basal insulins: evidence from Swedish real-world data. Curr Med Res Opin. 2017;33:647-55.

25. Karlsson G, Johannesson M. The decision rules of cost-effectiveness analysis. Pharmacoeconomics. 1996;9:113-20.

26. Monami M, Marchionni N, Mannucci E. Long-acting insulin analogues vs. NPH human insulin in type 1 diabetes. A meta-analysis. Diabetes Obes Metab. 2009;11:372-8.
27. Kristensen PL, Tarnow L, Bay C, Nørgaard K, Jensen $\mathrm{T}$, Parving $\mathrm{HH}$, et al. Comparing effects of insulin analogues and human insulin on nocturnal glycaemia in hypoglycaemia-prone people with type 1 diabetes. Diabet Med. 2017;34:625-31.

28. Monami M, Marchionni N, Mannucci E. Long-acting insulin analogues versus NPH human insulin in type 2 diabetes: a meta-analysis. Diabetes Res Clin Pract. 2008;81:184-9.

29. Suh DC, Aagren M. Cost-effectiveness of insulin detemir: a systematic review. Expert Rev Pharmacoecon Outcomes Res. 2011;11:641-55.

30. Palmer AJ, Roze S, Valentine WJ, Smith I, WittrupJensen KU. Cost-effectiveness of detemir-based basal/bolus therapy versus NPH-based basal/bolus therapy for type 1 diabetes in a UK setting: an economic analysis based on meta-analysis results of four clinical trials. Curr Med Res Opin. 2004;20:1729-46.

31. Palmer AJ, Valentine WJ, Ray JA, Foos V, Lurati F, Smith I, et al. An economic assessment of analogue basal-bolus insulin versus human basal-bolus insulin in subjects with type 1 diabetes in the UK. Curr Med Res Opin. 2007;23:895-901.

32. Johnston SS, Conner C, Aagren M, Smith DM, Bouchard J, Brett J. Evidence linking hypoglycemic events to an increased risk of acute cardiovascular events in patients with type 2 diabetes. Diabetes Care. 2011;34:1164-70.

33. Khunti K, Davies M, Majeed A, Thorsted BL, Wolden ML, Paul SK. Hypoglycemia and risk of cardiovascular disease and all-cause mortality in insulin-treated people with type 1 and type 2 diabetes: a cohort study. Diabetes Care. 2015;38(2):316-22.

34. Lung TW, Petrie D, Herman WH, Palmer AJ, Svensson AM, Eliasson B, Clarke PM. Severe hypoglycemia and mortality after cardiovascular events for type 1 diabetic patients in Sweden. Diabetes Care. 2014;37:2974-81.

35. Paty B. The role of hypoglycemia in cardiovascular outcomes in diabetes. Can J Diabetes. 2015;39(Suppl. 5):S155-9.

36. Snell-Bergeon JK, Wadwa RP. Hypoglycemia, diabetes, and cardiovascular disease. Diabetes Technol Ther. 2012;14(Suppl. 1):S51-8. 